\title{
Promoting editorial capacity in psychiatric journals in low and middle income countries (LAMIC)
}

\author{
J de Jesus Mari', CP Szabo², C Wu, LCW Lam4, L Wang', M Midin', M Irfan', C Kieling7, H Herrman ${ }^{8}$ \\ 1 Universidade Federal de São Paulo, Department of Psychiatry, São Paulo, Brazil \\ 2Division of Psychiatry, University of the Witwatersrand, Johannesburg, South Africa \\ ${ }^{3}$ Shanghai Archives of Psychiatry, China \\ 4East Asian Archives of Psychiatry, Hong Kong \\ ${ }^{5}$ Asean Journal of Psychiatr, Malaysia \\ ${ }^{6}$ Journal of Pakistan Psychiatric Society, Pakistan \\ ${ }^{7}$ Department of Psychiatry, Hospital de Clínicas de Porto Alegre Porto Alegre, Brazil \\ ${ }^{8}$ Orygen Youth Health Research Centre, The University of Melbourne \& Director, World Health Organization Collaborating Centre in \\ Mental Health, Melbourne, Australia, Secretary for Publications, World Psychiatric Association
}

\begin{abstract}
Under the auspices of the WPA section for publications, the WPA Task Force on publications has been actively involved in promoting editorial capacity in LAMIC countries through workshops. The workshops review selected journals from regions within the LAMIC group. The current workshop focused on Africa and Asia, with selected editors presenting content related to their journals. The aim was to establish the readiness for indexation in international databases, and to provide strategic input to facilitate this process. However, beyond indexation the workshop provided an opportunity to contribute towards improving quality of publications that would lead to a positive impact on mental health content in these regions. A further workshop is planned for Central and South American publications.
\end{abstract}

Key words: Psychiatry; Publishing; Education; Developing countries

Received: 15-11-2010

Accepted: 15-12-2010

\section{Introduction}

Mental health research, particularly related to health services and mental health policy, are scarce in low and middle income countries (LAMIC). ${ }^{1}$ Two recent surveys conducted in 2007 and 2009 by the WPA Taskforce on Research Dissemination identified the underrepresentation of psychiatric journals from LAMIC in the main international indexation databases. ${ }^{2-6} \mathrm{In}$ fact, only 5.5\% of the 235 journals listed under the Psychiatry and Substance Abuse categories in Medline and Web of Science are from middle income countries, and none comes from a low income country. ${ }^{3}$ In order to promote editorial capacity for LAMIC journals and thus enhance their chances of indexation, representatives from 5 non-indexed psychiatric journals - with a focus on Africa and Asia - participated in a workshop facilitated by members of the WPA Operational Committee on Publications - Helen Herrman, Jair Mari, Christian Kieling and Christopher P. Szabo, with Norman Sartorius, Zeping Xiao, Michael Phillips and

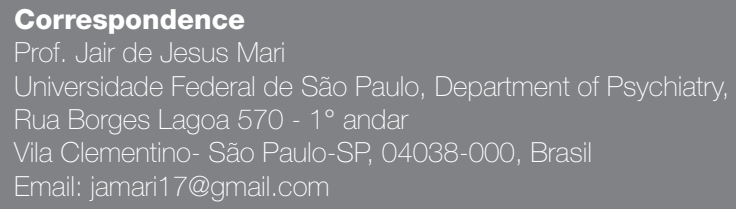

Shekhar Saxena as discussants. Prior to the meeting an invitation to participate in the workshop had been sent to identify non-indexed LAMIC based journals in Asia and Africa, with subsequent applications reviewed by members of the Operational Committee. The 5 journals were selected on the basis of an assessment of their preparedness to apply for selection to Medline according to previously described criteria ${ }^{5}$, with the purpose of assessing their current status and making recommendations for improving their quality and, consequently, their chances of selection.

\section{Indexed journals}

The workshop commenced with a general introduction regarding the aims, i.e., to assist with the process of selection to Medline and other databases. A previous, initial, workshop held in Prague in 2008 had included editors of 8 selected LAMIC psychiatric journals, with subsequent selection of 2 of these journals into Medline (African Journal of Psychiatry and Indian Journal of Psychiatry). The introduction was followed by presentations from the editors of two LAMIC psychiatric journals indexed in Medline (Revista Brasileira de Psiquiatria and African Journal of Psychiatry). These dealt with the experience of the process, lessons learned and future challenges beyond indexation. Aside from technical aspects that comprise requirements for selection, the political and strategic components of an application were also emphasized. 


\section{Non-indexed journals}

The meeting continued with a series of presentations from the selected journals which were the ASEAN Journal of Psychiatry (representing Malaysia, Thailand, Singapore, Indonesia and Phillipines), , East Asia Archives of Psychiatry (Hong Kong), Journal of the Pakistan Psychiatric Society (Pakistan) and Shanghai Archives of Psychiatry (China), and Current Psychiatry (Egypt). Each presentation covered specific aspects such as the journal's geographical reach, frequency of publication, content, review process, editorial structure and funding. Each presentation was evaluated in terms of apparent strengths, weaknesses and readiness for application, with direct feedback given. For the purposes of this publication each editor was requested to forward an abbreviated version of their presentation. Those received were published. The content which follows gives a broad overview of each publication and reveals the nature of challenges faced by these publications, with possible strategies that could contribute to improved quality, greater local and international relevance and potentially indexation in international databases.

\section{ASEAN Journal of Psychiatry}

The ASEAN Journal of Psychiatry is the scientific journal of ASEAN Federation of Psychiatry and Mental Health (AFPMH). It is also affiliated to the national psychiatric society of each member country. The Federation is representive of the countries of Association of Southeast Asian Nations (ASEAN) in mental health and psychiatry. The journal was founded in 1991, ten years after the formation of the Federation, with five participating member countries including Singapore, Malaysia, Indonesia, Thailand and the Philippines. The journal has been publishing 2 issues per year since 2007 containing an average of 10 articles per issue. Increasing the frequency of publication to 4 issues per year by 2011 is planned. Original articles comprise of $70 \%$ of all articles. The other types of articles include review papers, book reviews, short reports, case reports and letters to editor. Articles tend to come predominantly from only two or three of the participating countries. The journal is published solely in English. The rejection rate to date has been 10-20\%. In terms of accessibility for readers, the journal has been a free open access since 2007. Due to financial constraints, the journal has very limited hardcopy distribution. There is no plan to increase the number of the printed version but with better sharing of funding from the member countries in the near future, it is hoped the management of the online version could be upgraded. The target audiences are psychiatrists and mental health professionals. These include candidates doing degree, diploma, masters and doctorate in psychiatry.

The journal has an advisory board comprising of the current president of AFPMH and the presidents of the national psychiatric associations of each member country. It has an Editor-in-chief, a co-editor, eight associate editors, a list of reviewers and editorial board members from participating countries. The journal's editorship has been rotating every 2 years between the member countries with Malaysia holding this office for 2009-2010. Recognizing the weakness of this arrangement, the AFPMH committee members have recently agreed that Malaysia should retain the editorship for another 2 years.Based on the original purpose of the journal, it should cover all the 10 ASEAN countries. The other countries not mentioned above are Brunei Darussalam, Vietnam, Cambodia, Laos and Myanmar. Further effort is required to encourage participation from those countries in editorial matters, funding and publications.

Funding of the journal is managed by the country holding the editorship and is derived mainly from the national psychiatric association and commercial advertisements. It was agreed during the recent AFPMH committee meeting that funding for the journal will be shared between participating countries. The journal is not currently indexed in any databases.

\section{The East Asian Archives of Psychiatry}

The East Asian Archives of Psychiatry (EASAP) is a continuation of the Hong Kong Journal of Psychiatry. The editorial board has a strong International Advisory Board consisting of prominent academics in the field, comprising of active and emerging academic psychiatrists and mental health professionals in the East Asia region (Cambodia, China, Hong Kong, Indonesia, India, Japan, Korea, Singapore and Taiwan,). EASAP is circulated among fellows, member, inceptors, and affiliates of the Hong Kong College of Psychiatrists, mental health professionals and colleagues in other fields of medicine in Hong Kong, the Asia Pacific Region and over the world. It is an official publication of the Hong Kong College of Psychiatrists, being supported by advertisements, and the Hong Kong College of Psychiatrists, with a small amount from subscriptions. There are four issues per year, with 1,000 currently printed versions. Full text articles are available online at http:// www.easap.asia. 60 to $80 \%$ of the articles are original in content, published in English with a Chinese abstract. The rejection rate for the year 2009 was 51\%. The Journal is indexed in EMBASE, Excerpta Medica, PsyINFO, Index Copernicus, EBSCO, Thomson Gale and ProQuest. Full text is also available online at: www.hkjpsych.com. To improve indexation, the Advisory and Editorial Board have been greatly expanded with regional and international experts joining since 2010. Submissions from aspiring researchers in the developing region and mainland China will be actively solicited.

\section{Journal of Pakistan Psychiatric Society}

The Journal of Pakistan Psychiatric Society (JPPS), the official journal of Pakistan Psychiatric Society, is the only established Pakistani scientific journal dealing specifically with Psychiatry and Mental Health. The history of JPPS highlights the scientific development of psychiatry in general, and academic development of psychiatric research in particular, in Pakistan. The journal started as the Journal of Clinical Psychiatry, pioneering scientific publication of psychiatry in Pakistan but it could not maintain the continuity after a few issues. Journal of Pakistan Psychiatric Society was thus established in its present form in $2005 .{ }^{7}$

The editorial board is recently modified to develop in line with the current trends in medical journalism. It now comprises of 10 international and 11 national members apart from an advisory board. The members are renowned researchers and leading names in international psychiatry with a wide range of expertise in Psychiatry and a good number of publications to their name. They oversight and advise the journal on editorial policy, articles and contribution. The board is completely independent, with no pharmaceutical industry involvement.

The journal currently publishes 2 regular issues every year and it attracts and publishes more manuscripts from international scientific community than national. It regularly publishes features which include guest editorials (from an authority in the field, relevant to the issues from lower and middle income countries), Cochrane corner (abstracts from Cochrane systematic reviews with commentaries), special articles and debate etc. apart from the routine content. There is no charge to authors for publication. The journal does not publish any pharmaceutical sponsored articles. Information for readers and authors and free access to abstracts and full articles are provided through the website of the journal: www.jpps.com.pk.

The journal is recognized by the both the main national authorities i.e., Pakistan Medical and Dental Council and Higher Education Commission of Pakistan. The journal is indexed in the World Health Organization, Eastern Mediterranean Regional Office (EMRO); Directory of Open Access Journals (DOAJ), EBSCO Publishing's 
Electronic Databases; and MEDical Literature Indexing services Pakistan (MEDLIP)

The journal is dedicated to encourage and facilitate research at all levels and in all fields of psychiatry. It is predominantly devoted to reporting original investigations in the biomedical and health sciences relevant to the mental health. It aims to encourage and disseminate research related tot mental health problems as these relate to the socioeconomic and cultural context of lower and middle income countries, specifically Pakistan. It aspires to promote evidence based practice.

\section{Shanghai Archives of Psychiatry}

Shanghai Archives of Psychiatry is a bimonthly scientific journal prepared by Shanghai Mental Health Center and Shanghai Health Bureau. The journal was established by Shanghai Mental Health Center in 1959 and became a regular quarterly publication in 1989 and later bimonthly in 2003. It was the first academic journal dealing with mental health on the mainland. Articles related to all facets of mental health research and treatments are published in the journal. The main theme of the journal is psychiatric clinical practice. All scientific articles undergo rigorous peer review. The editorial board is composed of national and international specialists in psychiatry, who are prominent in research and practice in schizophrenia, mood disorders, anxiety disorders, child and adolescent psychiatry, geriatric psychiatry, forensic psychiatry, etc Their specialties cover psychopharmacology and biochemistry, genetics and psychotherapy. The rejection rate is about $55-60 \%$. The present chief editor is Prof. Jiang Kaida. All content is subject to peer review, and includes editorials, original articles, review articles, case reports, clinical experience presentation, conference discussion, conference proceedings, notice of training programs, etc. To date there have been 22 volumes. Each issue consists of between 11-13 original articles, 1-2 case reports and 4-5 reviews. The journal is published in Chinese, with abstracts in both English and Chinese for original articles.

The contributors and readership are national and include psychiatrists as well as other mental health professionals. The journal is abstracted or indexed in local Chinese databases and is available through subscription in both electronic or hardcopy format. Funding is provided by the Shanghai Mental Health Centre as well as through adverts in and subscriptions to the journal. Shanghai Archives of Psychiatry aims to attract more submissions from other areas of the country geographically, to improve the quality of published material, to invite leading figures in psychiatry to write for the journal and to be indexed in international databases. Difficulties experienced that need to be addressed include moving beyond a regional publication and becoming more nationally representative (including the possibility of a title change); delays in the peer review process; the inclination of Chinese and other researchers to publish in English language journals.

\section{Discussion}

Aside from discussion and suggestions related to each presentation, a number of proposals were made regarding future strategies:

1. The creation of a network of editors from developing world countries (indexed/non-indexed publications), to provide support and guidance as well as sharing of certain resources e.g. potential reviewers.

2. Provision of a check list of the format and content requirements a journal needs to fulfill for achieving indexation.

3. Supervision of steps to be taken and screening of applications before submission, by editors of indexed LAMIC journals.

4. Updating and further development of a database of all psychiatric journals, both indexed and non-indexed, from high and low and middle income nations. This content would be available through the WPA website and include details of the individual journals (cover; scope of content; submission process; indexing status) with links to their websites (where available)

\section{Conclusion - the future}

Based on the two workshops to date, and with the active support of the WPA Operational Committee on Publications, it is envisaged that beyond further journals being selected for Medline - and other databases - the main mission will be to enhance quality of journals related to mental health worldwide regardless of the indexation status. Providing local data, disseminated by an influential international journal is paramount to provide evidence based community care and to improve the quality of life of underserved patients and families from the LAMIC world. ${ }^{8} \mathrm{~A}$ further workshop is planned for the 15th World Congress of Psychiatry (to be held in Buenos Aires in 2011) with a focus on Central and South American countries.

\section{The content of this article constitutes a report of the Workshop at the World Psychiatric Association (WPA) International Congress, Beijing, China, September 2010}

\section{Acknowledgments}

The task force members (CPS, CK, $\mathrm{HH}$, and JM) as well as the five editors selected for the meeting have received funding for attending the workshop in Beijing. Michael Philips, Norman Sartorius and Shekhar Saxena, have made very solid and important contributions in the workshop. Prof. Mario Maj is very enthusiastic about this project and has given his kind support during his term as WPA President. Ms. Anna Engstrom provided both secretarial and logistical support in the organization of the event.

\section{References}

1. Sharan P, Gallo C, Gureje O, Lamberte E, Mari JJ, Mazzotti G, Patel V, Swartz L, Olifson S, Levav I, de Francisco A, Saxena S; Mental health research priorities in lowand middle-income countries of Africa, Asia, Latin America and the Caribbean. World Health Organization-Global Forum for Health Research - Mental Health Research Mapping Project Group. Br J Psychiatry. 2009; 195(4):354-63.

2. Herrman H, Kieling C, Mari Jde J. Working with the World Psychiatric Association to promote dissemination of mental health research worldwide. Rev Bras Psiquiatr. 2010; 32(1):4-5.

3. Kieling $C$, Herrman $H$, Patel V, Mari JD Indexation of psychiatric journals from lowand middle-income countries: a survey and a case study. World Psychiatry. 2009 Feb;8(1):40-44.

4. Kieling C, Herrman H, Patel V, Tyrer P, Mari JJ. A global perspective on the dissemination of mental health research. Lancet. 2009 Oct 31;374(9700):1500.

5. Mari JJ, Patel V, Kieling C, Anders M, Jakovljevi M, Lam LC, Lotaief F, Mendlowicz MV, Okulat G, Sathyanarayana Rao TS, Tamam L, Tyrer P, Herrman H. The 5/95 Gap on the dissemination of mental health research: The World Psychiatric Association (WPA) task force report on project with editors of low and middle income (LAMI) countrie.s. Afr J Psychiatry. 2009; 12(1):33-9

6. Mari JJ, Patel V, Kieling C, Razzouk D, Tyrer P, Herrman H. The 5/95 gap in the indexation of psychiatric joumals of low- and middle-income countries. Acta Psychiatr Scand. 2010 Feb;121(2):152-6.

7. Farooq S. JPPS recognized by Pakistan Medical and Dental Council but the challenge remains. JPak Psych Soc 2009; 6(2):50-1.

8. Thornicroft G, Alem A, Antunes Dos Santos R, Barley E, Drake RE, Gregorio G, Hanlon C, Ito H, Latimer E, Law A, Mari J, McGeorge P, Padmavati R, Razzouk D, Semrau M, Setoya Y, Thara R, Wondimagegn D. WPA guidance on steps, obstacles and mistakes to avoid in the implementation of community mental health care. World Psychiatry. 2010 Jun;9(2):67-77. 